\title{
Instar preference and parasitization of Aphis gossypii and Myzus persicae (Hemiptera: Aphididae) by the parasitoid Aphidius colemani (Hymenoptera: Aphidiidae)
}

\author{
Dionyssios Ch. PERDIKIS, Dionyssios P. LYKOURESSIS, Nikolaos G. GARANTONAKIS \\ and STYLIANH A. IATROU
}

\begin{abstract}
Agricultural University of Athens, Laboratory of Agricultural Zoology and Entomology, 75 Iera Odos, 11855 Athens, Greece; e-mail: lykouressis@aua.gr
\end{abstract}

Key words. Aphis gossypii, Myzus persicae, Aphidius colemani, host preference, parasitoid

\begin{abstract}
The instar preference and parasitization (expressed as mummification rate) of Aphis gossypii Glover and Myzus persicae (Sulzer) (Hemiptera: Aphididae) by the parasitoid Aphidius colemani Viereck (Hymenoptera: Aphidiidae) were studied at $25 \pm 0.5^{\circ} \mathrm{C}, 65 \pm 5 \%$ r.h. and a $16 \mathrm{~L}: 8 \mathrm{D}$ photoperiod. The female parasitoids were $24-36 \mathrm{~h}$ old and were left to forage for $1 \mathrm{~h}$ on an eggplant leaf on which 10 nymphs of each instar of $A$. gossypii or M. persicae were placed. The percentage of $A$. gossypii nymphs mummified was higher than that of $M$. persicae (43.2 and 25.2\%, respectively). The parasitoid parasitized nymphs of all instars of both aphid species, but it showed a preference for $1^{\text {st }}$ and $2^{\text {nd }}$ instars of $A$. gossypii and $1^{\text {st }}$ instar of $M$. persicae. Nymphs of both aphid species parasitized in the $1^{\text {st }}$ and $2^{\text {nd }}$ instars were mummified when reached the $4^{\text {th }}$ instar or adult stage, whereas those parasitized in the $3^{\text {rd }}$ and $4^{\text {th }}$ instars were mummified in the adult stage. The importance of these results in the effectiveness of $A$. colemani in biological control of $A$. gossypii and M. persicae is discussed.
\end{abstract}

\section{INTRODUCTION}

Aphidius colemani Viereck (Hymenoptera: Aphidiidae) is a polyphagous solitary endoparasitoid of aphids (Starý, 1975). Aphis gossypii Glover (Hemiptera: Aphididae) has been proved to be a highly suitable host for this parasitoid (Messing \& Rabasse, 1995; van Steenis, 1995; Harizanova \& Ekbom, 1997) whereas Myzus persicae (Sulzer) (Hemiptera: Aphididae) is an acceptable host of A. colemani (Tardieux \& Rabasse, 1986; van Steenis, 1993) that favours its performance (Hofsvang \& Hågvar, 1978; Toussidou et al., 1999). Furthermore, A. colemani was the most promising among four parasitoid species tested for biological control of M. persicae (van Steenis, 1995). This parasitoid is widely used in the biological control of $A$. gossypii in glasshouse crops (van Schelt et al., 1990; Grasswitz \& Reese, 1998; Eilenberg et al., 2000) and against M. persicae on eggplants (Easwaramoorthy et al., 1976; Bolckmans \& Tetteroo, 2002).

In biological control, host instar selection by a parasitoid is among the most important factors that affect its potential to reduce an aphid population, since it affects both aphid and parasitoid population increase (Hågvar \& Hofsvang, 1991). The host suitability has been considered to be a linear function of host size, but, although it is true in hosts that do not feed (Askew \& Shaw, 1986), it is not always the case in aphid parasitoids (Sequeira \& Mackauer, 1992). The optimal foraging theory predicts that host selection and acceptance aims at maximizing the profits of the next parasitoid generation (Hubbard \& Cook, 1978; Pyke, 1984). That is, the female takes care to ensure the most favourable environment for improving its progeny fitness, so that to increase its reproductive success rate. Host individuals may be suitable in terms to satisfy a minimum threshold for growth and development for the parasitoid larva but are presumably of different quality because different hosts can cover the nutritional needs of the developing parasitoid larva at a different success rate (Mackauer et al., 1996). The quality of the host could affect the size, sex ratio, longevity and fecundity of the adult parasitoid (Hågvar \& Hofsvang, 1991; Sequeira \& Mackauer, 1992; Pandey \& Singh, 1999).

Our knowledge on the factors that influence $A$. colemani host selection is relatively limited (Grasswitz, 1998) and it mainly concerns preference for different aphid species (Messing \& Rabasse, 1995; van Steenis, 1995). However, a foraging parasitoid when searching in an aphid colony encounters different types of prey and therefore, studies that examine parasitization rate and preference on different host types that are simultaneously present, are relevant to the natural field situation.

The objectives of the present work were to investigate: (1) the rate of parasitism and host instar preference of A. colemani when it was provided with all instars of A. gossypii or M. persicae and (2) the developmental stage at which parasitized aphid instars were mummified.

\section{MATERIAL AND METHODS}

\section{Insect rearing}

A culture of $A$. colemani was initiated from A. gossypii mummies collected on Hibiscus syriacus L. (Malvaceae) in Athens two years before the start of the experiments. During this period, the parasitoid culture was kept under its rearing conditions in the laboratory. The parasitoids cultures were developed on potted pepper plants (cv. Vidi) infested with M. persicae. M. persicae was reared on pepper plants and eggplants (cv. Bonica) whereas A. gossypii on eggplants. Both aphid species were initially collected on eggplants in the Campus of the Agricultural University of Athens. They were kept in woodframed cages $80 \times 80 \times 70 \mathrm{~cm}$, in a glasshouse with average temperature $22.5 \pm$ $2.5^{\circ} \mathrm{C}$ (mean \pm S.D.) under natural light.

Potted pepper plants bearing high infestations of $M$. persicae were covered separately with a plastic cage and were placed in a growth cabinet with $25 \pm 0.5^{\circ} \mathrm{C}, 65 \pm 5 \%$ r.h. and a $16 \mathrm{~L}: 8 \mathrm{D}$ photoperiod. Each cage was $11 \mathrm{~cm}$ in diameter and $30 \mathrm{~cm}$ in height. It was made of a PVC leaf $(0.4 \mathrm{~mm}$ thick $)$ with two lateral openings each of $9 \times 9 \mathrm{~cm}$, which together with the top 
opening of the cage, were covered with fine muslin. Then, 15-20 newly emerged parasitoids were released in each cage. At the emergence of the first parasitoids of the new generation drops of dilute honey were placed on the mouslin at the top of the cage, since it is a highly suitable food for survival of $A$. colemani adult (Hofsvang \& Hågvar, 1975). After two days the parasitoids emerged in the cage were collected by insect aspirator, and released to another plastic cage containing a pepper plant with aphids, for maintenance of the parasitoid rearing.

In the experiments parasitoids of less than $36 \mathrm{~h}$ old were used, which had not a previous contact with aphids. Pepperplant leaves bearing only mummies of $M$. persicae were introduced in a plastic cage of $20 \mathrm{~cm}$ in diameter and $30 \mathrm{~cm}$ high, otherwise similar to that described above. Also feeding on dilute honey and conditions inside the cabinet were identical. After $8 \mathrm{~h}$ from the first parasitoid emergence, parasitoids emerged were transferred in another similar cage and kept there for another $24 \mathrm{~h}$, to mate. Females were then carefully collected.

\section{Experimental procedure}

The oviposition preference of $A$. colemani females was investigated when provided simultaneously with equal numbers of all instars either of $A$. gossypii or $M$. persicae. The experiments were conducted in plastic Petri dishes $9 \mathrm{~cm}$ in diameter and 1 $\mathrm{cm}$ in height, with a round opening $3 \mathrm{~cm}$ in diameter at their top, covered with fine muslin. A layer of moistened cotton on the base of the dish was covered with a filter paper, on which a leaf of eggplant was put upside down. Ten individuals of each instar $\left(1^{\text {st }}, 2^{\text {nd }}, 3^{\text {rd }}\right.$ and $\left.4^{\text {th }}\right)$ either of $A$. gossypii or M. persicae were carefully transferred with a fine paintbrush and left for about $1 \mathrm{~h}$ to settle down on the leaf. Then, a female parasitoid subjected to the procedure described above, was introduced in the dish. After the first aphid was attacked, the dish was placed in a growth cabinet with conditions as above. The parasitoid was left in the dish for $1 \mathrm{~h}$. Then all aphids of the same instar were placed on an eggplant leaf in a separate dish. Mortality of aphids due to manipulations was checked in preliminary experiments $(0-5 \%)$ and was considered to be negligible.

The leaf in each dish was replaced with a new one every other day and the aphids were transferred on it. The number of mummies and the stage of the aphid at mummy formation were recorded daily for a period of 13 days. This period is long enough for emergence of mummies (Hofsvang \& Håvgar, 1975; Toussidou et al., 1999). After counting, mummies were removed from the dish. In each experiment 25 replicates (parasitoids) were used.

\section{Data analysis}

Oviposition data were analyzed using a 1 or 2-way ANOVA. Data on oviposition rate were root-square transformed whereas data on the percentage of aphids mummified in the $4^{\text {th }}$ instar were arcsin transformed before analysis. Means were separated using the Tukey-Kramer HSD test $(P=0.05)$. Analyses were conducted using the statistical package JMP (version 4.0.2, SAS Institute 2001).

The preference of each parasitoid among instars of each aphid species, was also evaluated using the Manly's index (Manly et al., 1972; Manly, 1974; Chesson, 1983). Manly's preference index:

$$
\beta j=\frac{\ln (r j / A j)}{\sum_{j=1}^{4} \ln (r j / A j)}, j=1,2,3,4
$$

where $\beta \mathrm{j}=$ Manly's Beta for hosts in aphid instar $j, r j=$ the number of hosts in aphid instar $\mathrm{j}$ not selected by the parasitoid, $A j$ the number of hosts in aphid instar $j$ available to the parasitoid. This index is based on the assumptions that all host types
TABLE 1. Number (mean $\pm \mathrm{SE}$ ) of Aphis gossypii and Myzus persicae nymphs mummified by Aphidius colemani, replicated 25 times, when aphids were exposed for $1 \mathrm{~h}$ to the parasitoid.

\begin{tabular}{ccc}
\hline Aphid instar & Aphis gossypii & Myzus persicae \\
\hline First & $5.92 \pm 0.17 \mathrm{a}$ & $3.44 \pm 0.69 \mathrm{a}$ \\
Second & $5.40 \pm 0.23 \mathrm{a}$ & $3.08 \pm 0.62 \mathrm{ab}$ \\
Third & $3.60 \pm 0.21 \mathrm{~b}$ & $2.08 \pm 0.41 \mathrm{bc}$ \\
Fourth & $2.44 \pm 0.20 \mathrm{c}$ & $1.52 \pm 0.30 \mathrm{c}$ \\
\hline
\end{tabular}

Values bearing the same lower case letters were not significantly different among instars (within columns) (Tukey-Kramer HSD test, $P<0.05$ ).

are encountered at random and the preference is independent of density. However, in cases that host exploitation is not negligible this is appropriate index (Cock, 1978; Chesson, 1983). The Manly's index values for each aphid instar were examined for significant difference that expectation based on the numbers of each aphid instar available using a t-test.

\section{RESULTS}

\section{Rate of parasitism}

The percentage of $A$. gossypii nymphs mummified by $A$. colemani per hour was significantly higher than that of $M$. persicae $\left(F_{1,48}=43.66, P<0.01\right)$, reaching a percentage of $43.23 \pm$ $4.74 \%$ and $25.20 \pm 3.81 \%$ (mean $\pm 95 \% \mathrm{CI}$ ) in each species, respectively.

\section{Oviposition preference}

The effect of instar was significant in the parasitoid oviposition rate on $A$. gossypii $\left(F_{3,96}=58.14, P<0.01\right)$. The number of $1^{\text {st }}$ instar nymphs parasitized was the highest, not differing significantly to that of the $2^{\text {nd }}$ instar (Table 1). Significantly more aphids were mummified in the $2^{\text {nd }}$ than $3^{\text {rd }}$ instar and finally, the number of $3^{\text {rd }}$ instar nymphs mummified was significantly higher than in the $4^{\text {th }}$ instar.

The number of aphids mummified was found to be significantly affected by the instar of $M$. persicae $\left(F_{3,96}=8.25, P<\right.$ $0.01)$. The number of $1^{\text {st }}$ instar nymphs mummified was the highest, not differing significantly to that of the $2^{\text {nd }}$ instar (Table 1). A similar number of aphids were mummified in the $2^{\text {nd }}$ and $3^{\text {rd }}$ instars and also in the $3^{\text {rd }}$ and $4^{\text {th }}$ instars.

The values of Manly's preference index for each instar of $A$. gossypii are presented in Table 2 . This index was significantly higher than the expected in the $1^{\text {st }}$ and $2^{\text {nd }}$ instars whereas the preference for $3^{\text {rd }}$ and $4^{\text {th }}$ instar aphids was significantly lower than the expected.

The values of Manly's preference index for each instar of $M$. persicae are also shown in Table 2 . This index was significantly higher than the expected in the $1^{\text {st }}$ instar aphids. In the $2^{\text {nd }}$ and $3^{\text {rd }}$ instar a significant preference was not recorded whereas the preference for $4^{\text {th }}$ instar aphids was significantly lower than the expected.

TABLE 2. Manly's preference index of Aphidius colemani for nymphs of Aphis gossypii and Myzus persicae.

\begin{tabular}{cll}
\hline Aphid instar & Aphis gossypii & Myzus persicae \\
\hline First & $0.386^{* * *}$ & $0.367^{* * *}$ \\
Second & $0.333^{* *}$ & 0.297 \\
Third & $0.189^{*}$ & 0.218 \\
Fourth & $0.081^{* * *}$ & $0.126^{* * *}$ \\
\hline
\end{tabular}

Significant differences between the values of estimated Manly's indices and the expected; $*-P<0.05 ; * *-P<0.01$; $* * *-P<0.001$. 


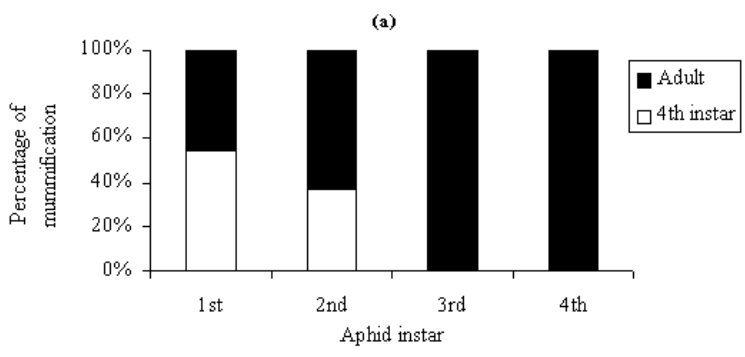

(b)

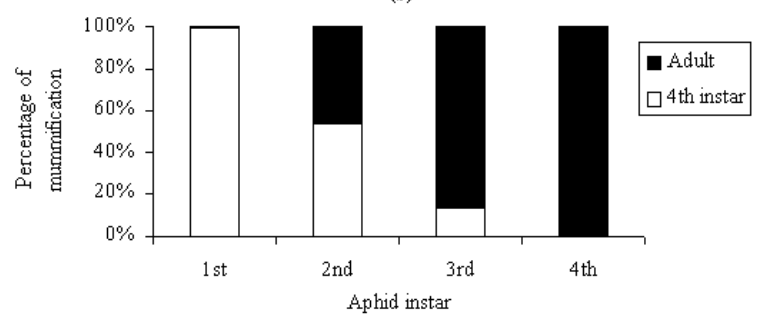

Fig. 1. Percentage of the parasitized nymphs in each instar of Aphis gossypii (a) and Myzus persicae (b) that were mummified in the $4^{\text {th }}$ instar or adult.

\section{Stage of aphid at mummification}

The percentage of each instar aphids that were mummified in the $4^{\text {th }}$ instar or in the adult stage is shown in Fig. 1. The percentage of aphids mummified in the $4^{\text {th }}$ instar was found to depend on both aphid species and aphid instar at parasitization $\left(1^{\text {st }}, 2^{\text {nd }}\right.$ or $\left.3^{\text {rd }}\right)\left(F_{1,139}=50.73, P<0.01\right.$ and $F_{2,139}=182.03, P<$ 0.01 , respectively). That percentage was similar in the $1^{\text {st }}$ and $2^{\text {nd }}$ instars of $A$. gossypii but it was significantly reduced in the $3^{\text {rd }}$ instar (Fig. 1a), whereas, in instars of M. persicae, it was significantly reduced with instar increase (Fig. 1b). Between the two species, significantly less individuals of the $1^{\text {st }}$ instar were mummified in the $4^{\text {th }}$ instar of $A$. gossypii than M. persicae.

\section{DISCUSSION}

It is confirmed here that both $A$. gossypii and $M$. persicae are acceptable hosts for $A$. colemani. Most interestingly, the parasitoid showed a higher mummification rate on $A$. gossypii than $M$. persicae (Table 1). This is consistent with the results of van Steenis (1993) who also recorded a higher parasitization on $A$. gossypii (70-80\%) than M. persicae (47-56\%) by A. colemani reared on sweet pepper with $M$. persicae. A. colemani has also been found to exhibit a preference for A. gossypii compared to M. persicae (Wellings et al., 1994; Messing \& Rabasse, 1995). In the current study this conclusion seems to be further supported considering that although $A$. colemani was reared on $M$. persicae for a 2-year period, its preference for A. gossypii remained strong. Also, A. colemani rearing on M. persicae for 1.5 years did not alter its preference for $A$. gossyppii than when reared on $A$. gossypii (van Steenis, 1995). This preference for $A$. gossypii than the larger $M$. persicae could be due to the time limitations when ovipositing, which is a determinant of parasitoid searching behaviour (Mackauer et al., 1992). In addition, among the range of their hosts, polyphagous parasitoids show preference for those hosts which are physiologically more suitable (Messing \& Rabasse, 1995).

It was shown that $A$. colemani prefers to oviposit mainly on $1^{\text {st }}$ but also $2^{\text {nd }}$ instars of $A$. gossypii and $1^{\text {st }}$ instars of $M$. persicae (Tables 1,2). Young nymphs are usually preferred by aphid parasitoids (Hågvar \& Hofsvang, 1991) and it has also been documented in Monoctonus paulensis (Ashmead) (Hymenoptera: Braconidae) (Chau \& Mackauer, 2000). The preference for small aphids has been related to their less developed defense and escape reactions against the foraging parasitoid (Gerling et al., 1990; Kouame \& Mackauer, 1991; Losey \& Denno, 1998) but also to their higher suitability for parasitoid fitness (Liu, 1985).

The stage in aphid life at which mummification takes place is important in biological control, because parasitized aphids that develop to adults may produce offspring. In our case, almost all nymphs of $A$. gossypii and M. persicae parasitized in the $3^{\text {rd }}$ and $4^{\text {th }}$ instars reached to adulthood before becoming mummies and therefore they could reproduce. According to van Steenis \& ElKhawass (1995) $4^{\text {th }}$ instars of $A$. gossypii parasitized by $A$. colemani could reach the adult stage but give only a small number of offspring. However, the parasitized $1^{\text {st }}$ and $2^{\text {nd }}$ instars were mainly mummified at the $4^{\text {th }}$ instar (Fig. 1). Therefore, the preference of $A$. colemani to oviposit in young instars accompanied with their low survival rate to adult stage, indicates a very likely important characteristic of $A$. colemani involved in its effectiveness in biological control.

According to the results, nymphs of $1^{\text {st }}, 2^{\text {nd }}$ and $3^{\text {rd }}$ instar of $A$. gossypii were mummified at a higher percentage in the adult stage than those of $M$. persicae (Fig. 1). In other words, $A$. gossypii can continue its development while parasitized by $A$. colemani more successfully than M. persicae. This extension in aphid life could favour parasitoid fitness and could be related with the preference that $A$. colemani shows to A. gossypii.

The preference of a parasitoid to oviposit on young instars could be considered as an advantage for its use as a biological control agent, because young nymphs are more numerous than larger ones (Hughes, 1963; Kouame \& Mackauer, 1991). Therefore, the present study indicates that host preference could be an important factor for effectiveness of $A$. colemani against $A$. gossypii and M. persicae. Moreover, if we consider that young instars emerge in the early stages of an aphid infestation, then $A$. colemani should have the ability to suppress the aphid population at the early stages of its increase.

In conclusion, the results show that $A$. gossypii and M. persicae are suitable hosts of $A$. colemani. However, the higher parasitization (expressed as mummification) rate in $A$. gossypii than in $M$. persicae indicates that this parasitoid could reduce more effectively $A$. gossypii than $M$. persicae infestations if other factors had an equal effect on the population increase of the aphids. Furthermore, it was demonstrated that $A$. colemani prefers to oviposit on young instars of both aphid species. This characteristic could be essential for its effectiveness against $A$. gossypii but also $M$. persicae on vegetable crops, as well as for more appropriate mass rearing techniques of this parasitoid. However, further research is needed to investigate whether such a preference is related with an improved performance of the parasitoid since host selection for solitary parasitoids should be based between the fitness gain per egg and the economics of search time allocation (Kuame \& Mackauer, 1991).

\section{REFERENCES}

Askew R.R. \& Shaw M.R. 1986: Parasitoid communities: their size, structure and development. In Waage J. \& Greathead D. (eds): Insect Parasitoids. Academic Press, London, pp. 225-264.

Bolckmans K.J.F. \& Tetteroo A.N.M. 2002: Biological pest control in eggplants in the Netherlands. IOBC/WPRS Bull. 25(1): 25-28.

Chau A. \& Mackauer M. 2000: Host-instar selection in the aphid parasitoid Monoctonus paulensis (Hymenoptera: Braconidae, Aphidiinae): a preference for small pea aphids. Eur. J. Entomol. 97: 347-353.

Chesson J. 1983: The estimation and analysis of preference and its relationship to foraging models. Ecology 64: 1297-1304. 
Cock M.J.K. 1978. The assessment of preference. Ecology 47: 805-816.

Easwaramoorthy S., Chelliah S. \& Jayaraj S. 1976: Aphidius platensis Brethes - a potential parasite of Myzus persicae (Sulz.). Madras Agric. J. 63: 182-183.

Eilenberg J., Enkegaard A., Vestergaard S. \& Jensen B. 2000 Biocontrol of pests on plant crops in Denmark: Present status and future potential. Biocontrol Sci. Technol. 10: 703-716.

Gerling D., Roitberg B.D. \& Mackauer M. 1990: Instarspecific defence of pea aphid, Acyrthosiphon pisum: influence on oviposition success of the parasite Aphelinus asychis (Hymenoptera: Aphelinidae). J. Insect Behav. 3: 501-514.

Grasswitz T.R. 1998: Effect of adult experience on the hostlocation behavior of the aphid parasitoid Aphidius colemani Viereck (Hymenoptera: Aphidiidae). Biol. Control 12: 177-181.

Grasswitz T. R. \& Reese B. D. 1998: Biology and host selection behaviour of the aphid hyperparasitoid Alloxysta victrix in association with the primary parasitoid Aphidius colemani and the host aphid Myzus persicae. BioControl 43: 261-271.

HÅgvar E.B. \& Hofsvang T. 1991: Aphid parasitoids (Hymenoptera: Aphidiidae): biology, host selection and use in biological control. Biocontrol News Inform. 12: 13-41.

Harizanova V. \& Еквом B. 1997: An evaluation of the parasitoid, Aphidius colemani Viereck (Hymenoptera: Braconidae) and the predator Aphidoletes aphidimyza Rondani (Diptera: Cecidomyiidae) for biological control of Aphis gossypii Glover (Homoptera: Aphididae) on cucumber. J. Entomol. Sci. 32: 17-24.

Hofsvang T. \& HÅgvaR E.B. 1975: Duration of development and longevity in Aphidius ervi and Aphidius platensis (Hym. Aphidiidae), two parasites of Myzus persicae (Hom.: Aphididae). Entomophaga 20: 11-22.

Hofsvang T. \& HÅgVaR E.B. 1978: Larval morphology and development of Aphidius colemani Viereck and Ephedrus cerasicola Starý (Hym., Aphidiidae). Norw. J. Entomol. 25: $1-8$.

HUBBARD S.F. \& CoOK R.M. 1978: Optimal foraging by parasitoid wasps. J. Anim. Ecol. 47: 593-604.

Hughes R.D. 1963: Population dynamics of the cabbage aphid, Brevicoryne brassicae (L.). J. Anim. Ecol. 32: 393-424.

KouAme K.I. \& MackAUER M. 1991: Influence of aphid size, age and behaviour on host choice by the parasitoid wasp Ephedrus californicus: a test of host-size models. Oecologia 88: 197-203.

LIU S.S. 1985: Development, adult size and fecundity in Aphidius sonchi reared in two instars of its aphid host, Hyperomyzus lactucae. Entomol. Exp. Appl. 37: 41-48.

Losey J.E. \& Denno R.F. 1998: The escape response of pea aphids to foliar-foraging predators: Factors affecting dropping behaviour. Ecol. Entomol. 23: 53-61.

Mackauer M., Bai B., Chow A. \& Danyk T. 1992: Asymmetric larval competition between two species of solitary parasitoid wasps: the influence of superparasitism. Ecol. Entomol. 17: 233-236.

Mackauer M., Michaud J.P. \& VöLKL W. 1996: Host choice by aphidiid parasitoids (Hymenoptera: Aphidiidae): host recognition, host quality, and host value. Can. Entomol. 128: 959-980.

MANLY B.F.J. 1974: A model for certain types of selection experiments. Biometrics 30: 281-294.

Manly B.F.J., Miller P. \& CoOK L.M. 1972: Analysis of a selective predation experiment. Am. Nat. 106: 719-736.

Messing R.H. \& Rabasse J.M. 1995: Oviposition behaviour of the polyphagous aphid parasitoid Aphidius colemani Viereck (Hymenoptera: Aphidiidae). Agric. Ecosyst. Environ. 52: $13-17$.

PANDEY S. \& Singh R. 1999: Host size induced variation in progeny sex ratio of an aphid parasitoid Lysiphlebia mirzai. Entomol. Exp. Appl. 90: 61-67.

PYKE G.H. 1984: Optimal foraging theory: a critical review. Annu. Rev. Ecol. Syst. 15: 523-575.

S.A.S. Institute Inc. 2001. JMP IN version 4.0.2.

van Schelt J., Douma J.B. \& Raveneberg W.J. 1990: Recent developments in the control of aphids in sweet pepper and cucumber. W.P.R.S./I.O.B.C. Bull. 13/5:190-193.

Sequeira R. \& Mackauer M. 1992: Nutritional ecology of an insect host parasitoid association: the pea aphid - Aphidius ervi system. Ecology 73: 183-189.

STARÝ P. 1975: Aphidius colemani Viereck: its taxonomy, distribution and host range (Hymenoptera, Aphidiidae). Acta Entomol. Bohemoslov. 72: 156-163.

van SteEnIs M.J. 1993: Suitability of Aphis gossypii Glov., Macrosiphum euphorbiae (Thom.) and Myzus persicae Sulz. (Hom: Aphididae) as host for several aphid parasitoid species (Hym: Braconidae). W.P.R.S./I.O.B.C. Bull. 16(2): 157-160.

van STEENIS M.J. 1995: Evaluation of four aphidiine parasitoids for biological control of Aphis gossypii. Entomol. Exp. Appl. 75: $151-157$.

van Steenis M.J. \& El-Khawass K.A.M.H. 1995: Life history of Aphis gossypii on cucumber: influence of temperature, host plant and parasitism. Entomol. Exp. Appl. 76: 121-131.

TARDIEUX I. \& Rabasse J.M. 1986: Some aspects of host immunity and physiological suitability in aphids attacked by Aphidius colemani. In Niemczyk E. \& Dixon A.F.G. (eds): Ecology and Effectiveness of Aphidophaga. S.P.B. Academic Publishing, The Hague, pp. 311-315.

Toussidou M., Williams M.C. \& Leather S. 1999: Life history parameters of Aphidius colemani (Hym.: Aphidiidae) on sweet pepper in different temperature regimes. W.P.R.S./ I.O.B.C. Bull. 22(1): 255-258.

Wellings P.W., Hart P.J., Kami V. \& Morneau D.C. 1994: The introduction and establishment of Aphidius colemani Viereck (Hym., Aphidiidae) in Tonga. J. Appl. Entomol. 118: 419-428.

Received October 22, 2003; revised January 29, 2004, accepted March 15, 2004 